\title{
Lessons from Training Liberian Public School Teachers in
}

Neuroscience

J. Cooper ${ }^{1}$, J. Dubinsky², M. Leona ${ }^{3}$, K. Brick ${ }^{4}$, J. Monmia ${ }^{3}$.

${ }^{1}$ The Carter Center, Liberia Mental Health Program, Atlanta, USA.

Janice.cooper@cartercenter.org

2University of Minnesota, Neuroscience, Minneapolis, USA. Dubin001@umn.edu

${ }^{3}$ The Carter Center, Liberia Mental Health Program, Monrovia, Liberia.

${ }^{4}$ Peace Corps Liberia, Education, Monrovia, Liberia.

\section{Objectives}

A train-the trainer professional development program was initiated in Monrovia, Liberia to increase teacher knowledge of brain function, development and mental health. The training was designed to foster student mental health and optimal learning. It supported teachers in a low resource, high demand learning environment with evidence-based pedagogy.

\section{Background}

After a devastating civil war and Ebola crisis, Liberian teachers need support and training. They lack information on the science of brain development or the impact of their interactions on children's development, mental health and behavior.

\section{Materials and Methods}

Twenty-four Tier I teachers received workshop content focused on the biological basis of learning and memory (BrainU.org) over 2 weeks. The presenting neuroscientist modeled best practices in inquiry education. Teachers discussed pedagogies to enhance learning. A leadership team comprised of 8 Tier I teachers adapted the contents to local needs and subsequently delivered four 1 week workshops to 92 science teachers (Tier II). During 2 day refresher sessions, 3-6 months later, the neuroscientist answered questions via Skype and teachers shared implementation strategies, problems and successes and discussed inquiry based methods in-depth. Teachers completed knowledge tests, surveys, daily reflections, interviews and were observed by trainers in model classrooms.

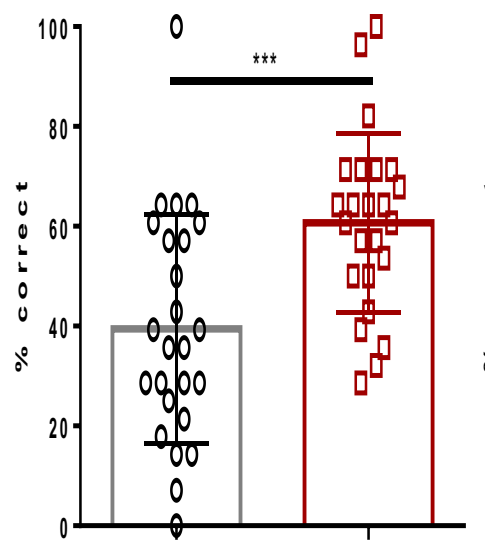

Neuroscience Knowledge. Understanding of synaptic plasticity and the post neurobiology of learning improved in both teacher cohorts. Tier I and II tests had 13 and 4 questions, respectively. Dubinsky et al 2019 The Neuroscientist. https://doi.org/10.11777/1073858419835447.

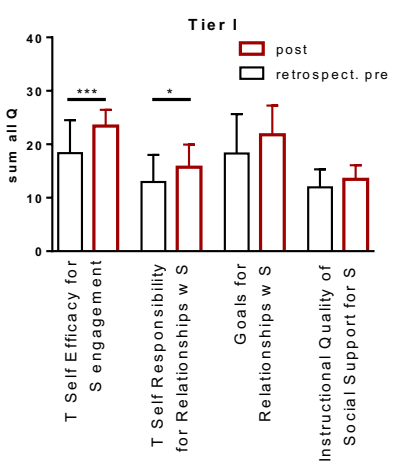

Social Emotional Support. Teachers pedagogical attitudes towards building positive relationships with students improved. Subscales from OECD survey for teacher general pedagogical knowledge. Sonmark, K. et al. 2017 OECD Education Working
Papers, No. 159, OECD Publishing, Paris http://dx.doi.org/10.1787/43332ebd-en

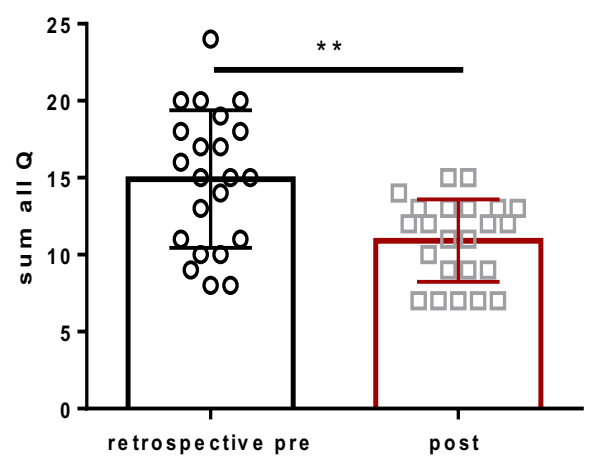

Tier II

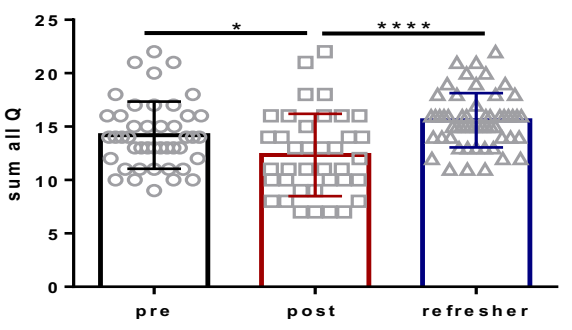

Stigma. General Perceptions of how to treat persons with mental illness improved after the workshop. Kohrt et al 2018 International Review Psychiatry 30:182

${ }^{*}, * *, * * *, * * * *=p<0.05,0.01,0.001,0.0001$

Tier I - two tailed $t$ tests; Tier II - one way ANOVA with Bonferonni corrections.

\section{Conclusions}

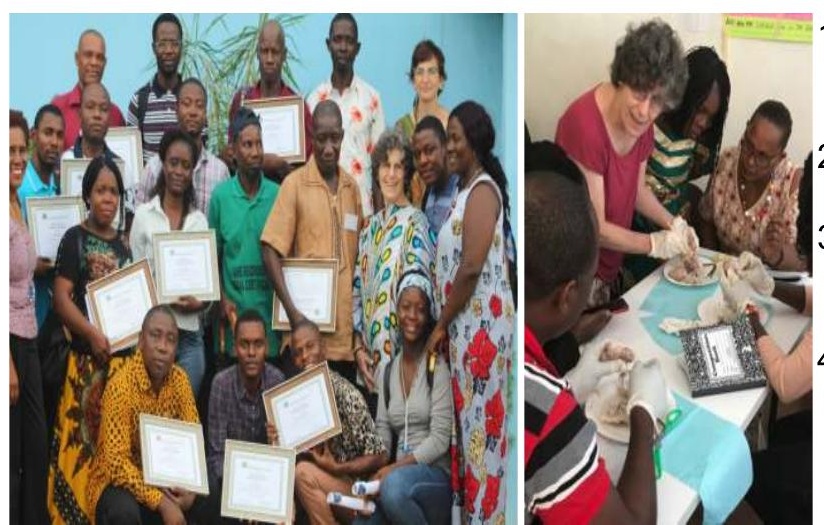

1. Both Tier I \& II science teachers learned neuroscience. The Trainthe-Trainer neuroscience teacher professional development was successful.

2. Teachers' social and emotional support for students was strengthened.

3. Teachers' negative attitudes towards mental illness and epilepsy were diminished by the end of the training but not sustained upon return to their classrooms.

4. Understanding neuroscience has the potential to positively influence teacher attitudes and support for students social, emotional and behavioral needs. Longer trainings and follow-up support will be needed for long lasting impacts. 